УДК 66.067

\title{
МЕТОДЫ УДАЛЕНИЯ ПИГМЕНТОВ ИЗ СТОЧНЫХ ВОД
}

Джубари Мохаммед Кадер 1 , mohammedqader1983@gmail.com

Алексеева Надежда Вячеславовна², alexejewa.nadja@gmail.com

Базияни Гашин Ибрахим³, gasheenbazeany@gmail.com

Таха Виляль Саад ${ }^{4}$, bilalsaad_t@yahoo.com

1 Северный технический университет, Ирак, 36001, г. Мосул, ул. Аль-Саяда, 1530.

2 Тамбовский государственный технический университет, Россия, 392000, г. Тамбов, ул. Советская, 106.

3 Тамбовский государственный университет им. Г.Р. Державина, Россия, 392000, г. Тамбов, ул. Интернациональная, 33.

4 Завод по очистке воды Кармат Али, Басра ойл компани, Ирак, 61001, Басра, ул. Баб-Аль-Зубайр, 520.

Актуальность. Красители и пигменты - это природные и ксенобиотические соединения, которые находят широкое применение в различных областях деятельности человека за счет способности придавать объектам ивет. В ходе реализации технологического процесса производства с применением пигментов образуются промывные воды, содержащие пигмент, которые чаще всего являются сточными водами. В результате предприятие теряет часть ценных пигментов и красителей, а окружающая среда подвергается техногенному воздействию. Различные красители, присутствующие в воде, оказывают неблагоприятное воздействие на окружающую среду. Следовательно, очистка сточных вод от пигментов является актуальной проблемой.

Цель: нахождение наиболее эфрфективного и экономически выгодного технологического процесса очистки сточных вод от пигментов и красителей.

Методы: сбор, обобщение и комплексный анализ данных по методам очистки сточных вод от красителей и пигментов.

Результаты. Рассмотрены существующие технологии очистки сточных вод, содержащих пигменты и красители. Приведены примеры российского и зарубежного опыта. Показана невозможность создания единой технологии очистки сточных вод, содержащих пигменты и красители, так как на выбор конкретного процесса очистки влияют характеристики сточных вод, обусловленнье технологией производства и видом пигментов и красителей. Тем не менее можно систематизировать существующие технологии для более удобного и быстрого выбора необходимого технологического процесса. Описаны механические, массообменные, химические и биологические процессы очистки. Проведен анализ отдельных процессов и комбинации нескольких. Использование нескольких процессов в одной технологической стадии разделения сточных вод является наиболее эффрективным и экономически выгодным решением.

\section{Ключевые слова:}

Текстильные сточные воды, красители, физическая очистка, биодеградация, адсорбция, мембранная очистка.

\section{Введение}

Очистка воды в настоящее время представляет собой одно из важнейших направлений прикладной науки. Сбросы сточных вод сложного состава, содержащих пигменты, вызывают серьёзную обеспокоенность у природоохранных регулирующих органов [1]. Неиспользованные в производстве вещества сбрасываются со сточными водами, которые характеризуются высокими показателями цветности, биохимического потребления кислорода (БПК), химического потребления кислорода (ХПК), pН, температуры, мутности и содержания токсичных химических веществ. Ряд промышленных сточных вод содержат различные типы красителей, которые из-за высокой молекулярной массы и сложной структуры имеют очень низкую биоразлагаемость [2, 3]. Кроме того, прямой сброс таких вод в канализационные сети приводит к нарушению процессов биологической очистки. Такие сточные воды могут иметь широкий диапазон значений $\mathrm{pH}$, высокие концентрации солей, таких как $\mathrm{Na}_{2} \mathrm{SO}_{4}$ и $\mathrm{NaCl}$, а также карбонаты [4]. Таким образом, эти стоки с высокими концентрациями неорганических солей, кислот и оснований в биологических реакторах вызывают увеличение затрат на очистку [5]. Существует ряд методов, которые используются для удаления красителей. К ним относятся: биологическая обработка, коагуляция/флокуляция, химическое окисление и фотокаталитические процессы, озонообработка, мембранные процессы и адсорбция [6]. Рассмотрим указанные методы более подробно. 


\section{Красители и пигменты}

Цвет вводится в красящие материалы с использованием красителей и пигментов. Красители можно определить как растворимые окрашенные вещества, которые применяются в виде растворов, в то время как пигменты - это нерастворимые соединения, интегрированные в результате диспергирования в такие продукты, как краски, печатные краски и пластмассы [7]. Красители классифицируют на катионные, анионные и неионные. Хромофорами в анионных и неионных красителях являются в основном азогруппа или антрахиноны. В результате разрушения азо-связи в сточных водах образуются токсичные амины [8].

По мнению М.В. Bogacki и др. [9], пигменты можно разделить на две категории: гомогенные пигменты и смеси. Однородные пигменты содержат частицы пигментов аналогичного типа, например цветные оксиды металлов и металлические порошки. Вторую группу смеси - получают химическим окрашиванием подходящего носителя, такого как активный высокодисперсный кремнезем, осажденный карбонат кальция. Смеси также могут быть получены механическим смешиванием интенсивно окрашивающего пигмента с наполнителем.

Следует отметить, что объемы производства промышленности и ее сточных вод увеличиваются пропорционально, что делает ее одним из основных источников серьезных проблем загрязнения во всем миpe. В частности, выброс окрашенных сточных вод в окружающую среду нежелателен не только из-за их окраски, но и потому, что многие красители из сточных вод и продукты их распада токсичны и/или являются мутагенами [10]. Было подсчитано, что более 10-15 \% общего количества красителей, используемых в производстве, выбрасываются в окружающую среду в процессе синтеза и окрашивания [11]. Без адекватной обработки красители стабильны и могут оставаться в окружающей среде в течение длительного периода времени [12]. Помимо проблемы загрязнения, промышленность связывают с потреблением большого количества питьевой воды (в некоторых случаях до $3000 \mathrm{~m}^{3} /$ сут) [11]. Во многих странах, где питьевая вода в дефиците, такое высокое ее потребление невозможно, и было рекомендовано перерабатывать сточные воды для их повторного использования. Большое значение с точки зрения охраны окружающей среды имеет и состав красящих веществ.

\section{Применение пигментов и красителей}

Человечество использовало красители на протяжении тысяч лет. Считается, что неандерталец был первым человеком, который использовал красители около 180000 лет назад. В 1856 г. William Henry Perkin открыл первый в мире коммерчески успешный синтетический краситель, и к концу XIX в. было разработано и изготовлено уже 10000 новых синтетических красителей [13].

Таблица 1. Основные характеристики красителей [7]

Table 1. Main characteristics of dyes [7]

\begin{tabular}{|c|c|c|}
\hline $\begin{array}{c}\text { Класс } \\
\text { красителей } \\
\text { Dye class }\end{array}$ & $\begin{array}{l}\text { Описание } \\
\text { Description }\end{array}$ & $\begin{array}{c}\text { Виды загрязнителей, связанных } \\
\text { с различными красителями } \\
\text { Types of pollutants associated with various dyes }\end{array}$ \\
\hline $\begin{array}{l}\text { Кислотный } \\
\text { Acid }\end{array}$ & $\begin{array}{l}\text { Анионные соединения с высокой растворимостью в воде } \\
\text { Anionic compounds with high water solubility }\end{array}$ & $\begin{array}{l}\text { Цвет; органические кислоты; незафиксированные красители } \\
\text { Colour; organic acids; unfixed dyes }\end{array}$ \\
\hline $\begin{array}{l}\text { Основной } \\
\text { Basic }\end{array}$ & $\begin{array}{l}\text { Очень яркие водорастворимые катионные красители, } \\
\text { которые используются в слабокислых красящих ваннах } \\
\text { Very bright dyes, water-soluble cationic dyes, applied in } \\
\text { weakly acidic dye baths }\end{array}$ & $\begin{array}{l}\text { Цвет; органические кислоты; незафиксированные краси- } \\
\text { тели } \\
\text { Colour; organic acids; unfixed dyes }\end{array}$ \\
\hline $\begin{array}{l}\text { Прямой } \\
\text { Direct }\end{array}$ & $\begin{array}{l}\text { Водорастворимые анионные соединения можно наносить } \\
\text { непосредственно на целлюлозу без фиксатора красителя } \\
\text { Water-soluble, anionic compounds can be applied directly } \\
\text { to cellulosic without mordants (a substance that will form a } \\
\text { coordination complex with the dye. Useful in setting dyes } \\
\text { on fabrics) }\end{array}$ & $\begin{array}{l}\text { Цвет; соль; незафиксированный краситель; катионные } \\
\text { фиксирующие агенты; поверхностно-активное вещество; } \\
\text { пеногаситель; выравнивающие и замедляющие агенты; } \\
\text { отделка; разбавители } \\
\text { Colour; salt; unfixed dye; cationic fixing agents; surfactant; } \\
\text { defoamer; leveling and retarding agents; finish; diluents }\end{array}$ \\
\hline $\begin{array}{l}\text { Дисперс- } \\
\text { ный } \\
\text { Disperse }\end{array}$ & $\begin{array}{l}\text { Нерастворимы в воде } \\
\text { Water insoluble }\end{array}$ & $\begin{array}{l}\text { Цвет; органические кислоты; носители; выравнивающие } \\
\text { агенты; фосфаты; пеногасители; смазки; диспергаторы; } \\
\text { разбавители } \\
\text { Colour; organic acids; carriers; leveling agents; phosphates; } \\
\text { defoamers; lubricants; dispersants; diluents }\end{array}$ \\
\hline $\begin{array}{l}\text { Протравной } \\
\text { Mordant }\end{array}$ & $\begin{array}{l}\text { Окончательный цвет во многом зависит от выбора фик- } \\
\text { сатора красителя (протравы). Примером протравы яв- } \\
\text { ляется дихромат калия } \\
\text { Final colour is largely dependent on the choice of mordant. } \\
\text { An example of mordant is potassium dichromate }\end{array}$ & $\begin{array}{l}\text { Фиксатор красителя (особенно в категориях тяжелых ме- } \\
\text { таллов) высоко токсичен } \\
\text { Mordants (particularly in heavy metals categories) will cause } \\
\text { hazardous to health }\end{array}$ \\
\hline $\begin{array}{l}\text { Активный } \\
\text { Reactive }\end{array}$ & $\begin{array}{l}\text { Водорастворимые анионные соединения, самый боль- } \\
\text { шой класс красителей } \\
\text { Water-soluble, anionic compounds, the largest dye class }\end{array}$ & $\begin{array}{l}\text { Цвет; соль; щелочи; незафиксированный краситель; по- } \\
\text { верхностно-активные вещества; пеногасители; разбавите- } \\
\text { ли; отделка } \\
\text { Colour; salt; alkali; unfixed dye; surfactants; defoamer; } \\
\text { diluents; finish }\end{array}$ \\
\hline $\begin{array}{l}\text { Сернистый } \\
\text { Sulphur }\end{array}$ & $\begin{array}{l}\text { Органические соединения, содержащие серу или суль- } \\
\text { фид натрия } \\
\text { Organic compounds containing sulphur or sodium sulphide }\end{array}$ & $\begin{array}{l}\text { Цвет; щелочи; окислители; восстановители; незафиксиро- } \\
\text { ванный краситель } \\
\text { Colour; alkali; oxidizing agents; reducing agent; unfixed dye }\end{array}$ \\
\hline $\begin{array}{l}\text { Кубовый } \\
\text { Vat }\end{array}$ & $\begin{array}{l}\text { Самые старые красители, химически более сложные, } \\
\text { нерастворимы в воде } \\
\text { Oldest dyes, more chemically complex, water insoluble }\end{array}$ & $\begin{array}{l}\text { Цвет; щелочь; окислители; восстановители } \\
\text { Colour; alkali; oxidizing agents; reducing agent }\end{array}$ \\
\hline
\end{tabular}


Синтетические красители - исключительно стойкие органические соединения. Они широко применяются в различных отраслях текстильной [14], целлюлозно-бумажной [15], кожевенной и дубильноэкстрактовой [16], пищевой промышленности [17], в сельском хозяйстве [18], при окраске волос [19] и др. Синтетические красители применяются для контроля эффективности очистки сточных вод [20], отслеживания подземных вод [21] и определения площади поверхности активного ила [20].

Химические классы красителей, которые наиболее часто используются в промышленных масштабах, это производные азо-, антрахинона, серы, трифенилметила и фталоцианина, индигоиды [22]. Существует более 100000 коммерческих красителей с приблизительной оценкой производства $7 \cdot 10^{5}-1 \cdot 10^{6}$ т в год [23]. Свойства и токсичность красителей, содержащихся в сточных водах, были широко изучены. Классы и описание красителей, типичные загрязнители, связанные с красителями, приведены в табл. 1.

\section{Доступные технологии удаления красителей}

Очистка промышленных сточных вод включает в себя четыре процесса, а именно: предварительную обработку, первичную очистку, вторичную очистку и третичную очистку. Процесс предварительной обработки включает стабилизацию и нейтрализацию промышленных сточных вод перед сбросом в муниципальные канализационные системы или в центральную промышленную канализационную систему. После стадии предварительной обработки используются физические или химические методы разделения (первичная очистка) для удаления взвешенных веществ в сточных водах с последующей вторичной очисткой. Вторичная биологическая обработка использует микроорганизмы для стабилизации компонентов отходов перед переходом к третичной обработке. Третичные процессы (физико-химическая обработка) включают адсорбцию, ионный обмен, химическое окисление и мембранное разделение. Заключительными стадиями процесса очистки сточных вод являются стадии переработки и удаления осадка [24].

Для удаления красителей из промышленных сточных вод используются различные химические, физические и биологические методы [25]. Эти методы могут использоваться отдельно или совместно в различных комбинациях. Обработка может сочетать две или более технологий для обеспечения эффективности процесса. Однако эксплуатационные расходы и время необходимое для достижения желаемой степени очистки, являются основными критериями выбора подходящего способа удаления красителя из сточных вод. Остановимся на методах очистки подробнее.

\section{Физические методы}

Физическая обработка включает в себя процессы разделения частиц; никаких значительных химических или биологических изменений не происходит. Примерами процессов физической обработки являются адсорбция, мембранная фильтрация и ионный обмен. Эти процессы зависят от размера частиц [26].

\section{Адсорбция}

Степень адсорбции зависит от природы адсорбата (его молекулярной массы, молекулярной структуры, размера молекул, полярности и концентрации раствора). Она также зависит от поверхностных свойств адсорбента, таких как размер частиц, площадь поверхности, поверхностный заряд и т. д. Эффективность процесса адсорбции определяется физикохимическими свойствами адсорбента и адсорбата. Кроме того, механизмы адсорбции можно разделить на физические и химические. При физической адсорбции загрязняющие вещества накапливаются на поверхности адсорбента в результате вышеуказанных взаимодействий. При химической адсорбции адсорбат химически связан с поверхностью адсорбента за счет электронного обмена [27].

Количество адсорбента для удаления красителя сильно зависит от начальной концентрации красителя. Влияние начальной концентрации красителя определяется непосредственным соотношением между концентрацией красителя и площадью поверхности адсорбента. В общем случае процент удаления красителя уменьшается с увеличением начальной концентрации красителя, что может быть связано с насыщением адсорбционных центров на поверхности адсорбента. С другой стороны, увеличение начальной концентрации красителя вызовет увеличение емкости адсорбента, и это может быть связано с высокой движущей силой массопереноса при высокой начальной концентрации красителя [28]. Еще одним существенным физико-химическим параметром процесса является температура, так как она изменяет адсорбционную емкость адсорбента [29].

Несколько лет назад было установлено, что использование активированного угля в качестве адсорбента в процессе адсорбции эффективно при очистке сточных вод, но стоимость активированного угля слишком высока. Поэтому возникает необходимость поиска более дешевых и эффективных адсорбентов. В последнее время ряд исследований был сосредоточен на недорогом адсорбенте, который может разрушать и поглощать красители из сточных вод [30].

\section{Мембранная фильтрация}

Мембранная фильтрация - это метод, который использует мембранные микропоры для фильтрации и селективные проницаемые мембраны для разделения определенных веществ в сточных водах. В настоящее время процесс мембранного разделения часто используется для извлечения красителей из сточных вод, в основном это баромембранные процессы (микрофильтрация, ультрафильтрация, нанофильтрация и обратный осмос). Мембранный процесс разделения это новая технология очистки с высокой эффективностью отделения, низким энергопотреблением, простая в эксплуатации и обладающая рядом других преимуществ [31]. В текстильной промышленности эти методы могут использоваться как для фильтрации, так и для рециркуляции богатых пигментами потоков, для мерсеризации и отбеливания сточных вод [32]. Отме- 
чено [33], что методы фильтрации пригодны для рециркуляции воды на текстильном производстве при низкой концентрации красителей в сточных водах, но не способны снизить содержание растворенных твердых веществ, что затрудняет повторное использование воды.

Ультрафильтрация успешно применяется для утилизации и переработки отходов и нерастворимых красителей (например, индиго, диспергированных), вспомогательных химических веществ (поливиниловый спирт) и воды. При этом ультрафильтрация не удаляет низкомолекулярные и растворимые красители (кислотные, реактивные, основные и др.). Эффективное удаление цвета достигается с помощью нанофильтрации и обратного осмоса [34]. Кроме того, повторное использование воды окрашенных сточных вод стало возможно благодаря обратному осмосу. Но для того, чтобы избежать мембранного обрастания, необходима предварительная обработка с коагуляцией и микрофильтрацией [32].

Специфическая температура и химический состав сточных вод определяют тип и пористость используемого фильтра [35]. Наконец, основными недостатками мембранной технологии являются высокие экономические затраты, загрязнение мембран и производство концентрированного красящего раствора, который необходимо обрабатывать [31]. Следует отметить что экстрагирование из мембран концентратов, таких как гидроксид натрия, используемый на стадии мерсеризации, или проклеивающих агентов, таких как поливиниловый спирт (ПВС), может снизить затраты на обработку [36].

\section{Ионообменный метод}

Процесс ионного обмена обычно используется для удаления неорганических солей и некоторых специфических органических анионных компонентов [8]. В то же время ионный обмен не получил широкого применения для очистки окрашенных сточных вод, главным образом из-за мнения, что ионообменники не могут быть использованы для широкого спектра красителей [37]. Сточные воды пропускают через ионообменную смолу до тех пор, пока доступные активные участки не будут насыщены. Таким образом, из содержащих краситель сточных вод можно удалять как катионные, так и анионные красители. К преимуществам этого способа можно отнести химическую стойкость ионообменных смол, получение вод, не содержащих красители, и возможность удаления растворимых красителей. Главным недостатком этого метода является стоимость. Органические растворители дороги, а метод ионного обмена не очень эффективен для дисперсных красителей [38].

Кроме того, можно разработать сорбционный способ очистки сточных вод от красителей с использованием анионообменных смол. Однако многие детали, такие как точная процедура регенеративной обработки, утилизация или ограничения относительно типа сточных вод, в которых он может быть использован, требуют уточнения [39].

\section{Химические методы}

Метод химической обработки используется для удаления красителей из сточных вод с добавлением химических реактивов.

Процесс Фентона $\left(\mathrm{H}_{2} \mathrm{O}_{2}-\mathrm{Fe}(\mathrm{II})\right)$

Реагент Фентона является подходящим реактивом для очистки сточных вод [40]. Он представляет собой раствор пероксида водорода $\mathrm{H}_{2} \mathrm{O}_{2}$ (окислитель), в который в качестве катализатора добавлены катионы $\mathrm{Fe}^{2+}$. Разложение пероксида водорода сопровождается образованием гидроксильных радикалов [41].

S. Hashemian и др. [42] провели исследование, в котором Фентоновское окисление метилового фиолетового в водном растворе описали уравнениями (1)-(6):

$$
\begin{gathered}
\mathrm{Fe}^{2+}+\mathrm{H}_{2} \mathrm{O}_{2} \rightarrow \mathrm{Fe}^{3+}+\mathrm{OH}^{*}+\mathrm{OH}^{-}, \\
\mathrm{OH}^{*}+\mathrm{H}_{2} \mathrm{O}_{2} \rightarrow \mathrm{H}_{2} \mathrm{O}+\mathrm{HO}_{2}{ }^{*}, \\
\mathrm{Fe}^{3+}+\mathrm{HO}_{2}{ }^{*} \rightarrow \mathrm{Fe}^{2+}+\mathrm{H}^{+}+\mathrm{O}_{2}, \\
\mathrm{Fe}^{2+}+\mathrm{HO}_{2}{ }^{*} \rightarrow \mathrm{Fe}^{3+}+\mathrm{HO}_{2}^{-}, \\
\mathrm{Fe}^{2+}+\mathrm{OH}^{*} \rightarrow \mathrm{Fe}^{3+}+\mathrm{OH}^{-}, \\
\mathrm{HO}_{2}{ }^{*}+\mathrm{OH}^{*} \rightarrow \mathrm{H}_{2} \mathrm{O}+\mathrm{O}_{2} .
\end{gathered}
$$

Общее уравнение деградации метилового фиолетового и образования углекислого газа и нитрат-иона выглядит следующим образом (уравнение 7):

$$
\mathrm{C}_{24} \mathrm{H}_{28} \mathrm{~N}_{3}{ }^{+}+57 \mathrm{H}_{2} \mathrm{O} \longrightarrow 24 \mathrm{CO}_{2}+142 \mathrm{H}^{+}+3 \mathrm{NO}_{3}{ }^{-}+138 \mathrm{e}^{-} .
$$

Реакция Фентона эффективна в обесцвечивании как растворимых, так и нерастворимых красителей. Одним из основных недостатков этого метода является образование осадка в результате флокуляции реагента и молекул красителя. Осадок, который содержит концентрированные примеси, все еще требует удаления. Обычно он сжигается с получением энергии, но некоторые считают, что такое удаление отнюдь не безвредно для окружающей среды. Производительность метода зависит от конечного состава осадка, хотя катионные красители вообще не коагулируют. Кислотные, прямые, кубовый, протравной и реактивный красители обычно коагулируют, но полученная масса плохо оседает, давая неудовлетворительные результаты [43].

\section{Процесс окисления}

Окисление представляет собой наиболее часто используемый химический метод удаления красителей. В основном это связано с простотой его применения. Основным окислителем является перекись водорода $\left(\mathrm{H}_{2} \mathrm{O}_{2}\right)$ [44]. Этот агент должен быть активирован, например, ультрафиолетовым светом. Химические способы удаления красителя варьируются в зависимости от способа, которым активируют $\mathrm{H}_{2} \mathrm{O}_{2}$ [40]. Окисление красителя в сточных водах сопровождается расщеплением ароматических колец его молекул [43].

Процесс окисления включает в себя перенос электронов (8), дегидрирование (9) и электрофильное присоединение к системам $\pi$ (гидроксилирование) (10). В результате этих реакций образуются органические радикалы и запускаются цепные процессы, в том числе реакции с кислородом (образование пероксид- 
ных радикалов), а полученные промежуточные продукты реакции подвергаются дальнейшему окислению частицами $\cdot \mathrm{OH}, \mathrm{HO}_{2}^{*}, \mathrm{H}_{2} \mathrm{O}_{2}$ до тех пор, пока органические загрязнители полностью не минерализуются [41].

$$
\begin{aligned}
& \cdot \mathrm{OH}+\mathrm{RX} \rightarrow \mathrm{RX}^{+*}+\mathrm{OH}^{-}, \\
& \cdot \mathrm{OH}+\mathrm{RH} \rightarrow \mathrm{R}^{*}+\mathrm{H}_{2} \mathrm{O}, \\
& \cdot \mathrm{OH}+\mathrm{PhX} \rightarrow \mathrm{PhX}(\mathrm{OH})^{*},
\end{aligned}
$$

где $\mathrm{RX}$ и $\mathrm{PhX}$ - алифатические и ароматические галогены соответственно.

\section{Озонирование}

Озон в качестве окислителя был впервые использован в начале 1970-х гг. Он является хорошим окислителем из-за высокой нестабильности (окислительный потенциал 2,07) по сравнению с пероксидом водорода $\mathrm{H}_{2} \mathrm{O}_{2}(1,78)$. Восстанавливаясь, озон разлагает хлорированные углеводороды, фенолы, пестициды и ароматические углеводороды [33].

Озон обладает высоким окислительным потенциалом и селективностью по отношению к органическим загрязнителям и генерирует $\mathrm{OH}^{*}$ по уравнениям (11)-(13) [45]

$$
\begin{gathered}
\mathrm{O}_{3}+\mathrm{e}^{-} \rightarrow \mathrm{O}_{3}^{*}, \\
\mathrm{O}_{3}^{*}+\mathrm{H}^{+} \rightarrow \mathrm{HO}_{3}^{*}, \\
\mathrm{HO}_{3}^{*} \rightarrow \mathrm{O}_{2}+\mathrm{OH}^{\circ} .
\end{gathered}
$$

Таким образом, процесс озонирования приводит к усиленному образованию $\mathrm{OH}^{*}$, тем самым повышая эффективность удаления красителя.

Количество озона, необходимое для окисления сточных вод, содержащих красители, зависит от об- щей цветности и остаточного ХПК, подлежащего удалению без формирования осадка и токсичных метаболитов [46]. Озонирование обесцвечивает сточные воды, делает их пригодными для сброса в природные водоемы. Этот метод предпочтителен для красителей с двойными связями в молекулах [40]. Одним из главных преимуществ озона является то, что он может использоваться в газообразном состоянии и поэтому не увеличивает объем сточных вод и осадков. Недостаток озонирования - его короткий период полураспада, обычно 20 минут. Это время уменьшается, если присутствуют красители, в то время как стабильность зависит от присутствия солей, $\mathrm{pH}$ и температуры [33].

\section{Биологические методы}

Биологические методы очистки используют микроорганизмы, главным образом бактерии, для разложения органических веществ в сточных водах. Этот метод обработки относительно недорог, имеет низкие эксплуатационные расходы, а конечные продукты полной минерализации нетоксичны и стабильны [23]. По сравнению с химическими и физическими методами обработки, биологические методы требуют меньше энергии и химических реактивов [47]. Как правило, биологические методы обработки делят на аэробные (с участием кислорода) и анаэробные (бескислородные) [48]. В аэробных системах в качестве акцептора электронов выступает кислород. А в анаэробной системе акцептором электронов является органическое вещество. На рис. 1 показаны принципы функционирования двух процессов биологической очистки [49].
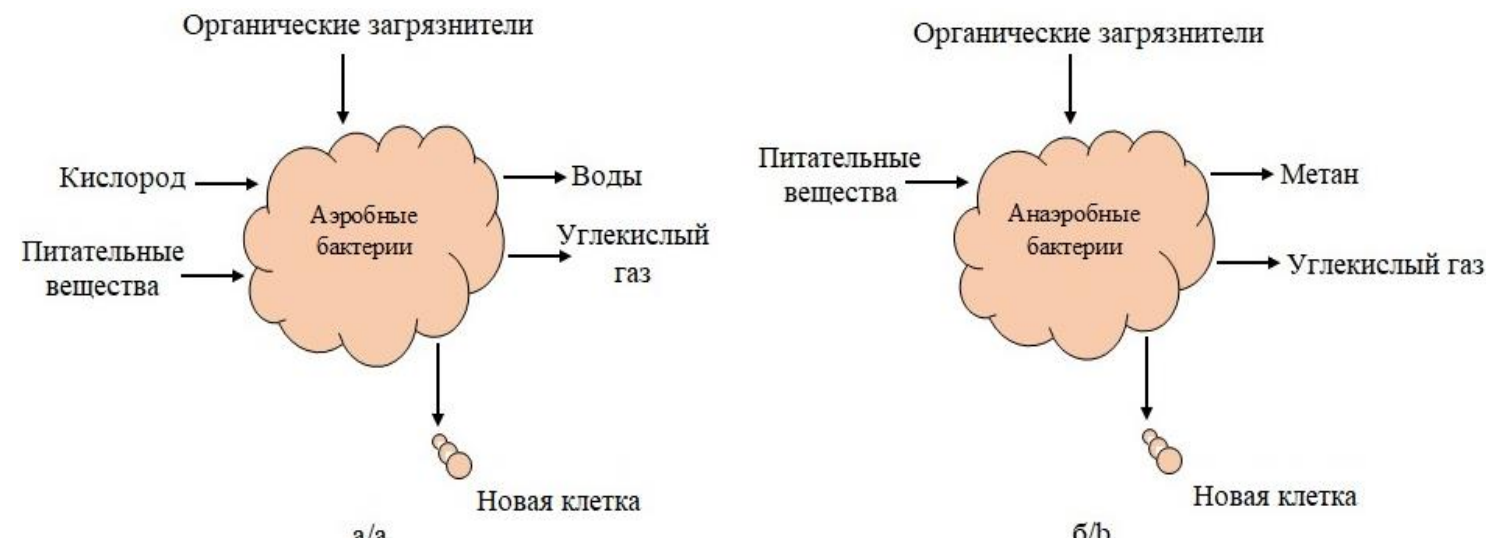

Pис. 1. Аэробная (а) и анаэробная (б) биологическая очистка сточных вод

Fig. 1. Aerobic (a) and anaerobic (b) biological wastewater treatment

Кислород используется в качестве окислителя органических веществ, а конечными продуктами в аэробной системе являются углекислый газ, вода и новые клетки. В анаэробной системе воздух отсутствует (следовательно, молекулярного свободного кислорода нет), и конечные продукты - метан, углекислый газ и новые клетки [49].

В то же время в литературе имеется много данных о способности чистых культур обесцвечивать красители $[50,51]$, но они не находят большого примене- ния в системах очистки промышленных сточных вод из-за неоднородности компонентов в сточных водах в зависимости от графика производства.

На самом деле эффективность методов биологической деградации зависит от адаптивности выбранных микробов и активности ферментов. Поэтому большое количество микроорганизмов и ферментов выделялось и испытывалось на разложение сразу нескольких красителей. 


\section{Аэробная очистка}

Аэробная биологическая обработка может очистить воду с помощью аэробных бактерий и факультативных бактерий в анаэробной среде. Эта очистка включает в себя два типа процессов: процессы в активном иле и процессы в биопленке.

\section{Бактериальная обработка}

Использование бактерий для разложения азокрасителей началось в 1970-х гг. с сообщений о Bacillus subtilis, Aeromonas hydrophila и Bacillus cereus [52]. E. Idaka и др. [53] также описывали использование бактерий для биодеградации азокрасителей. Показано, что аэробная обработка с использованием бактерий эффективна для обесцвечивания более 80 \% промышленных сточных вод, содержащих азокрасители.

\section{Грибковая обработка}

Использование грибов в очистке сточных вод основано на потреблении ими органических веществ, что снижает ХПК и БПК сточных вод. Другой целью является получение некоторого полезного продукта, такого как грибковая биомасса, обогащенная белком, для корма животных или некоторые специфические грибковые метаболиты [13]. Некоторые исследователи изучали способность штаммов грибов обесцвечивать азо- и трифенилметан.

\section{Анаэробная обработка}

Использование анаэробного процесса при очистке сточных вод от красителей также изучалось с начала 1970-х гг. [23]. Неоднократно описывалась эффективность анаэробной обработки при разложении широкого спектра синтетических красителей [20]. Этот процесс обработки дешевле, чем аэробная очистка, потому что отсутствует дорогая аэрация и осадок при обработке не увеличивается в объеме. Анаэробная обработка помогает в обесцвечивании красителей, подготавливая их к дальнейшей аэробной обработке и деградации [54]. Как правило, при анаэробном разложении образуются метан и сероводород [55].

Таблица 2. Сравнение методов удаления красителей из сточных вод

Table 2. Comparison of methods for removing dyes from wastewater

\begin{tabular}{|c|c|c|c|c|}
\hline $\begin{array}{l}\text { Методы } \\
\text { Methods }\end{array}$ & $\begin{array}{c}\text { Преимущества } \\
\text { Advantages }\end{array}$ & $\begin{array}{c}\text { Недостатки } \\
\text { Disadvantages }\end{array}$ & $\begin{array}{c}\text { Типы красителей } \\
\text { Dye types }\end{array}$ & 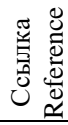 \\
\hline $\begin{array}{l}\text { Адсорбция } \\
\text { Adsorption }\end{array}$ & $\begin{array}{l}\text { Удаление широкого спектра кра- } \\
\text { сителей } \\
\text { Removal of wide variety of dyes }\end{array}$ & $\begin{array}{l}\text { Необходимы дорогостоящие расход- } \\
\text { ные материалы (адсорбентов) с по- } \\
\text { следующей их регенерацией или ути- } \\
\text { лизацией } \\
\text { Very expensive }\end{array}$ & $\begin{array}{l}\text { Щелочные красители } \\
\text { Basic dyes }\end{array}$ & [60] \\
\hline $\begin{array}{l}\text { Мембранная } \\
\text { фильтрация } \\
\text { Membrane filtration } \\
\end{array}$ & $\begin{array}{l}\text { Удаляет все типы красителей } \\
\text { Removes all dye types }\end{array}$ & $\begin{array}{l}\text { Образование слоя осадка в процессе } \\
\text { разделения } \\
\text { Concentrated sludge production }\end{array}$ & $\begin{array}{l}\text { Кислотные красители } \\
\text { Acid dyes }\end{array}$ & [61] \\
\hline $\begin{array}{l}\text { Ионный обмен } \\
\text { Ion exchange }\end{array}$ & $\begin{array}{l}\text { Возможность многократного ис- } \\
\text { пользования адсорбентов } \\
\text { Regeneration: no adsorbent loss }\end{array}$ & $\begin{array}{l}\text { Ограниченная область применения } \\
\text { Not effective for all dyes }\end{array}$ & $\begin{array}{l}\text { Активные красители } \\
\text { Reactive dyes }\end{array}$ & [62] \\
\hline $\begin{array}{l}\text { Окисление } \\
\text { Oxidation }\end{array}$ & $\begin{array}{l}\text { Быстрый и эффективный процесс } \\
\text { Rapid and efficient process }\end{array}$ & $\begin{array}{l}\text { Энергозатратно, расходы на реактивы } \\
\text { High energy cost, chemicals required }\end{array}$ & $\begin{array}{l}\text { Кислотный, активный, } \\
\text { прямой, катионный, } \\
\text { дисперсный и кубовый } \\
\text { красители } \\
\text { Acid, reactive, direct, } \\
\text { cationic, disperse, and vat } \\
\text { dye }\end{array}$ & [63] \\
\hline $\begin{array}{l}\text { Озонирование } \\
\text { Ozonation }\end{array}$ & $\begin{array}{l}\text { Применяется газообразный озон, } \\
\text { не приводит к увеличению объе- } \\
\text { ма сточных вод и осадка } \\
\text { Ozone can be applied in its gaseous } \\
\text { state and does not increase the } \\
\text { volume of wastewater and sludge }\end{array}$ & $\begin{array}{l}\text { Короткий период полураспада озона } \\
\text { Short half-life }\end{array}$ & $\begin{array}{l}\text { Активные красители } \\
\text { Reactive dyes }\end{array}$ & [64] \\
\hline $\begin{array}{l}\text { Аэробная обра- } \\
\text { ботка } \\
\text { Aerobic treatment }\end{array}$ & $\begin{array}{l}\text { Низкие эксплуатационные расхо- } \\
\text { ды и невысокое количество обра- } \\
\text { зующегося шлама } \\
\text { Lower running costs and produce } \\
\text { less sludge }\end{array}$ & $\begin{array}{l}\text { Невысокая скорость обработки кати- } \\
\text { онных красителей } \\
\text { Under aerobic conditions cationic dyes } \\
\text { are not readily metabolized }\end{array}$ & $\begin{array}{l}\text { Азокрасители } \\
\text { Azodyes }\end{array}$ & [65] \\
\hline $\begin{array}{l}\text { Анаэробная обра- } \\
\text { ботка } \\
\text { Anaerobic } \\
\text { treatment }\end{array}$ & $\begin{array}{l}\text { Позволяет обесцвечивать азо- и } \\
\text { другие водорастворимые красители } \\
\text { Allows azo- and other water-soluble } \\
\text { dyes to be decolorised }\end{array}$ & $\begin{array}{l}\text { Выделяются метан и сероводород } \\
\text { Anaerobic break down yields methane } \\
\text { and hydrogen sulphide }\end{array}$ & $\begin{array}{l}\text { Азокрасители } \\
\text { Azodyes }\end{array}$ & [65] \\
\hline $\begin{array}{l}\text { Коагуляция } \\
\text { Coagulation }\end{array}$ & $\begin{array}{l}\text { Низкая себестоимость очищен- } \\
\text { ной воды } \\
\text { Low cost of treated water }\end{array}$ & $\begin{array}{l}\text { Образование большого количества } \\
\text { осадка } \\
\text { High sludge production }\end{array}$ & $\begin{array}{l}\text { Дисперсные красители } \\
\text { Disperse dyes }\end{array}$ & [66] \\
\hline $\begin{array}{l}\text { Электрохимиче- } \\
\text { ское разрушение } \\
\text { Electrochemical } \\
\text { destruction }\end{array}$ & $\begin{array}{l}\text { Не используются химикаты, не } \\
\text { образуется шлам } \\
\text { No consumption of chemicals and } \\
\text { no sludge build up }\end{array}$ & $\begin{array}{l}\text { Относительно высокие скорости потока } \\
\text { снижают степень удаления красителя } \\
\text { Relatively high flow rates cause a direct } \\
\text { decrease in dye removal }\end{array}$ & $\begin{array}{l}\text { Активные красители } \\
\text { Reactive dyes }\end{array}$ & [67] \\
\hline
\end{tabular}


Большое внимание уделялось изучению влияния различных современных технологий на скорость разложения красителей и присутствия других соединений в средах. Так, было установлено, что разработка высокоскоростных систем, в которых гидравлическое время удержания не связано со временем удержания твердых частиц, облегчает удаление красителей из сточных вод текстильной промышленности [20]. Другое исследование доказало целесообразность использования анаэробного гранулированного осадка для полного удаления 20 азокрасителей [56]. Было показано, что применение редокс-медиатора антрахинона2,6-дисульфоновой кислоты сильно ускоряет разложение азокрасителей [57]. C.M. Carliell и др. изучено влияние присутствия солей (нитратов и сульфатов) на скорость разложения азокрасителя Реактивного красного 141 в анаэробных условиях. Результаты показали, что нитрат задерживает начало разложения, в то время как сульфат не влияет на процесс биодеградации [58].

В анаэробных условиях красители легко расщепляются, образуя ароматические амины, которые являются стабильным продуктом метаболизма. Органический углерод/источник энергии необходим для удаления красителей в метаногенных условиях. Для удаления красителей использовались простые субстраты, такие как глюкоза, крахмал, ацетат, этанол, сыворотка и тапиока [11]. G. Gnanapragasam и др. [59] изучали очистку текстильных сточных вод в иловом реакторе выше по течению. При 6,81 кг ХПК $/ \mathrm{m}^{3} /$ сут. удаление ХПК и красителя составило 96 и 93 \% соответственно с производством газа 355 л/сут. Исследователи показали, что ацидогенные, а также метаногенные бактерии способствуют удалению красителей.

В табл. 2 представлены преимущества и недостатки каждого рассмотренного метода, а также тип красителя, для которого этот метод может быть применен.

\section{Сочетание физико-химических методов}

Вообще, физические и химические методы на практике трудно разделить. Оба типа методов применяют химические реакции для улучшения качества воды. Коагуляция, мембранная фильтрация и передовые окислительные процессы, такие как озонирование, система $\mathrm{H}_{2} \mathrm{O}_{2}$ пиридин/ $\mathrm{Cu}$, процесс Фентона, фотокатализ и ультразвуковое облучение, объединяют и физико-химические, и химические методы обработки. Обычно физико-химические и химические процессы обработки экономически целесообразны, но иногда они весьма дорогостоящие из-за химических реактивов [68].

Красители обладают канцерогенными, мутагенными, аллергенными и токсическими свойствами. Также они являются причиной загрязнения окружающей среды. Высокие значения БПК и ХПК красителя, $\mathrm{pH}$ и присутствие металлов затрудняют очистку текстильных сточных вод. По этим причинам необходимо сочетать физические, химические и биологические процессы очистки [69].

Кроме того, при физических и химических методах используются коагулянты, такие как соли железа или полихлорид алюминия, для образования комплексов с красителями, которые затем отделяются фильтрацией или осаждением. Полиэлектролит можно также дозировать во время фазы флокуляции для улучшения свойств. Метод коагуляции-флокуляции является одним из наиболее широко используемых процессов на текстильных очистных сооружениях во многих странах, таких как Германия и Франция [70]. Элементы традиционной физико-химической обработки представлены на рис. 2 [8].

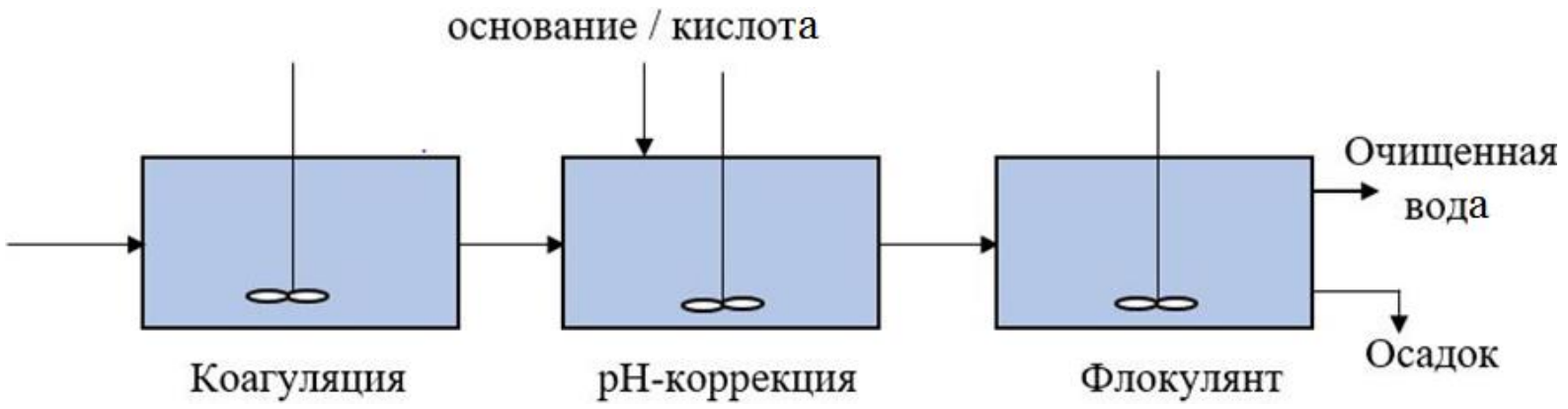

Pис. 2. Элементы традиционной физико-химической обработки

Fig. 2. Components of conventional physico-chemical treatment

В табл. 3 показаны некоторые экономически выгодные и высоко энергоэффективные сочетания физических, химических и биологических методов очистки окрашенных сточных вод, характеризующихся высокими значениями ХПК и высокими концентрациями органических соединений, таких как фенолы, красители и тензоактивные вещества [24].

Таким образом, было предложено использовать комбинированные процессы для нивелирования недостатков отдельных процессов.

\section{Заключение}

В данной работе описаны различные методы обесцвечивания промышленных сточных вод - физические, химические и биологические. Отмечено, что экономически эффективное удаление цвета сточных вод остается актуальной проблемой. Экологические проблемы, порождаемые промышленностью, все чаще привлекают повышенное внимание из-за загрязненных сточных вод, которые в основном образуются в процессе крашения. 
Таблица 3. Комбинация различных методов очистки

Table 3. Combination of various treatment methods

\begin{tabular}{|c|c|}
\hline $\begin{array}{l}\text { Комбинированный метод } \\
\text { Mixed method }\end{array}$ & $\begin{array}{l}\text { Процесс } \\
\text { Process }\end{array}$ \\
\hline $\begin{array}{l}\text { Физико-химический } \\
\text { (коагуляция/адсорбция) } \\
\text { Physical/chemical or chemical/physical } \\
\text { Coagulation/adsorption }\end{array}$ & $\begin{array}{l}\text { Коагуляция использовалась в качестве основного процесса очистки с последующей ад- } \\
\text { сорбцией для удаления активных красителей (С. І. Реактивный Красный } 45 \text { и С. I. Реак- } \\
\text { тивный Зеленый 8) из синтетических сточных вод. } \\
\text { Coagulation was used as a main treatment process followed by adsorption for the removal of } \\
\text { reactive dyes (C.I. Reactive Red } 45 \text { and C.I. Reactive Green 8) from synthetic wastewater }\end{array}$ \\
\hline $\begin{array}{l}\text { Коагуляция-флокуляция/адсорбция } \\
\text { Coagulation-flocculation/adsorption }\end{array}$ & $\begin{array}{l}\text { Удаление Черного } 5 \text { и оранжевого } 16 \text { исследовали комбинированным методом коагуля- } \\
\text { ции-флокуляции/адсорбции. } \\
\text { Removal of Black } 5 \text { and Orange } 16 \text { was investigated using combined coagulation- } \\
\text { flocculation/adsorption method }\end{array}$ \\
\hline $\begin{array}{l}\text { Коагуляция- } \\
\text { флокуляция/нанофильтрация } \\
\text { Coagulation-flocculation/nanofiltration }\end{array}$ & $\begin{array}{l}\text { В раствор } \mathrm{FeCl}_{3} \text { был использован в качестве коагулянта для удаления Ремазол черный } \\
133 \text { Б, Procion Малиновый H-EXL, Procion Темно-синий H-EXL, Procion Желтый H-EXL, } \\
\text { Procion Синий H-EXL. } \\
\text { FeCl3 was used as coagulant agent for removal of Remazol Black } 133 \text { B, Procion Crimson H- } \\
\text { EXL, Procion Navy H-EXL, Procion Yellow H-EXL, Procion Blue H-EXL }\end{array}$ \\
\hline $\begin{array}{l}\text { Процесс Фентона/Нанофильтрация } \\
\text { Fenton's process/nanofiltration }\end{array}$ & $\begin{array}{l}\text { Исследованы три комбинации процесса Фентона и нанофильтрации с использованием } \\
\text { синтетического раствора красителя эозина: например, реакция Фентона, за которой сле- } \\
\text { дует нанофильтрация; нанофильтрация, за которой следует реакция Фентона. } \\
\text { Three combinations of Fenton's process and nanofiltration are studied using a synthetic } \\
\text { solution of eosin dye: for example, Fenton’s process followed by nanofiltration; Nanofiltration } \\
\text { followed by Fenton's process; Scheme } 3 \text { is two steps of nanofiltration }\end{array}$ \\
\hline $\begin{array}{l}\text { Химический/биологический или био- } \\
\text { логический/химический } \\
\text { Фотокаталитический/анаэробный } \\
\text { Chemical/biological or } \\
\text { biological/chemical } \\
\text { Photocatalytic/anaerobic }\end{array}$ & $\begin{array}{l}\text { Фотокаталитический процесс на основе иммобилизованного диоксида титана был ис- } \\
\text { пользован в качестве метода пред-/пост-биологической анаэробной обработки для обра- } \\
\text { ботки азо-, антрахиноновых и фталоцианиновых текстильных красителей. } \\
\text { Photocatalytic process based on immobilized titanium dioxide was used as pre/posttreatment } \\
\text { method to biological anaerobic treatment for the treatment of azo, anthraquinone, and } \\
\text { phthalocyanine textile dyes }\end{array}$ \\
\hline $\begin{array}{l}\text { Озонирование/биологическая деграда- } \\
\text { ция с использованием биопленки } \\
\text { Ozonation/biological } \\
\text { degradation with biofilm }\end{array}$ & $\begin{array}{l}\text { Очистка сточных вод от красителей с помощью озонирования, приводящая к образова- } \\
\text { нию токсичных и канцерогенных побочных продуктов. } \\
\text { Treatment of dye wastewater using ozonation produces toxic and carcinogenic by-products }\end{array}$ \\
\hline
\end{tabular}

Выбор способа удаления красителя будет зависеть от характеристик сточных вод, таких как класс и концентрация красителя, $\mathrm{pH}$, соленость и токсичность соединений. Большинство промышленных сточных вод, содержащих анионные и катионные красители, очищаются адсорбцией. Недорогие, доступные на местном уровне и эффективные материалы могут использоваться в качестве адсорбентов вместо дорогостоящего коммерческого активированного угля для удаления красителей из водного раствора. Недорогие адсорбенты имеют ряд преимуществ для коммерческого использования в будущем.

Методы химической обработки, такие как усовершенствованные процессы окисления и коагуляциифлокуляции, эффективны при обработке широкого спектра водных растворов красителей, но удаление

\section{СПИСОК ЛИТЕРАТУРЫ/REFERENCES}

1. Deaconu M., Senin R., Stoica R., Athanasiu A., Crudu M., Oproiu L., Ruse M., Filipescu C. Adsorption decolorization technique of textile/leather-dye containing effluents. International Journal of Waste Resources, 2016, vol. 6, no. 2, pp. 1-7.

2. Queiroz M.T.A., Queiroz C.A., Alvim L.B., Sabará M.G., Leão M.M.D., De Amorim C.C. Restructuring in the flow of textile wastewater treatment and its relationship with water quality in Doce River, MG, Brazil. Gestão\&Produção, 2019, vol. 26, no. 1 , pp. 1-14.

3. Pala A., Tokat E. Color removal from cotton textile industry wastewater in an activated sludge system with various additives. Water research, 2002, vol. 36, no. 11, pp. 2920-2925.

4. Karcher S., Kornmüller A., Jekel M. Anion exchange resins for removal of reactive dyes from textile wastewaters. Water Research 2002, vol. 36, no. 19, pp. 4717-4724. осадка все еще остается проблемой. Озонирование, фотокаталитические и сонокаталитические методы деградации все чаще используются в очистке сточных вод, поскольку они не увеличивают объем сточных вод и осадков, но образование токсичных побочных продуктов препятствует их широкому распространению.

Использование бактерий и грибов не соответствует требованиям процессов очистки из-за их короткого срока службы и неустойчивого характера в присутствии токсичных текстильных стоков. Наиболее перспективным процессом является использование комбинированных методов удаления красителей из сточных вод благодаря высокому качеству очищенной воды. Таким образом, все методы обесцвечивания, описанные в данном обзоре, имеют свои преимущества и недостатки.

5. Yaseen D.A., Scholz M. Textile dye wastewater characteristics and constituents of synthetic effluents: a critical review. International Journal of Environmental Science and Technology, 2019, vol. 16, no. 2, pp. 1193-1226.

6. Ahmad A., Mohd-Setapar S.H., Chuong C.S., Khatoon A., Wani W.A., Kumar R., Rafatullah M. Recent advances in new generation dye removal technologies: novel search for approaches to reprocess wastewater. RSC Advances, 2015, vol. 5, no. 39, pp. 30801-30818.

7. Teng T.T., Low L.W. Removal of Dyes and Pigments from Industrial Effluents. Advances in Water Treatment and Pollution Prevention. Dordrecht, Springer, 2012. $460 \mathrm{p}$.

8. Mostafa M. Waste water treatment in textile industries - the concept and current removal technologies. Journal of Biodiversity and Environmental Sciences, 2015, vol. 7, no. 1, pp. 501-525.

9. Bogacki M.B., Michalska I., Krysztafkiewicz A. Application of experimental design for optimization of physicochemical proper- 
ties of the inorganic pigment, iron(III) silicate. Dyes and Pigments, 2004, vol. 61, no. 2, pp. 149-164.

10. Khan S., Malik A. Environmental and health effects of textile industry wastewater. Environmental deterioration and human health. Dordrecht, Springer, 2014. 421 p.

11. Sarayu K., Sandhya S. Current technologies for biological treatment of textile wastewater - a review. Applied Biochemistry and Biotechnology, 2012, vol. 167, no. 3, pp. 645-661.

12. Carmen Z., Daniela S. Textile organic dyes - characteristics, polluting effects and separation/elimination procedures from industrial effluents - a critical overview. Organic pollutants ten years after the Stockholm convention-environmental and analytical update 2012, vol. 10, pp. 1-33.

13. Sharma S.K., Sanghi R. Advances in water treatment and pollution prevention. Dordrecht, Springer Science \& Business Media, 2012. $460 \mathrm{p}$.

14. Firmino P.I.M., Da Silva M.E.R., Cervantes F.J., Dos Santos A.B Colour removal of dyes from synthetic and real textile wastewaters in one- and two-stage anaerobic systems. Bioresource Technology, 2010, vol. 101, no. 20, pp. 7773-7779.

15. Tahir U., Yasmin A., Khan U.H. Phytoremediation: potential flora for synthetic dyestuff metabolism. Journal of King Saud University - Science, 2016, vol. 28, no. 2, pp. 119-130.

16. Misra M., Akansha K., Sachan A., Sachan S.G. Removal of dyes from industrial effluents by application of combined biological and physicochemical treatment approaches. In: Combined Application of Physico-Chemical \& Microbiological Processes for Industrial Effluent Treatment Plant. Singapore, Springer, 2020. 406 p.

17. Ntrallou K., Gika H., Tsochatzis E. Analytical and sample preparation techniques for the determination of food colorants in food matrices. Foods, 2020, vol. 9, no. 1, pp. 1-27.

18. Berber-Villamar N.K., Netzahuatl-Muñoz A.R., Morales-Barrera L. Chávez-Camarillo G.M., Flores-Ortiz C.M., Cristiani-Urbina E Corncob as an effective, eco-friendly, and economic biosorbent for removing the azo dye Direct Yellow 27 from aqueous solutions. PLOS ONE, 2018, vol. 13, no. 4, pp. 1-30.

19. Jayanthi C.R., Divyashree R.N., Vijayalakshmi, Dharani S., Soumya R. A cross sectional study of hair dye use among doctors and nurses working at a tertiary care centre. International Journal of Research in Pharmacology \& Pharmacotherapeutics, 2018 , vol. 7, no. 1, pp. 85-96.

20. Forgacs E., Cserháti T., Oros G. Removal of synthetic dyes from wastewaters: a review. Environment International, 2004, vol. 30 no. 7 , pp. $953-971$

21. Cowie R., Williams M., Wireman M., Runkel R. Use of natura and applied tracers to guide targeted remediation efforts in an aci mine drainage system, Colorado Rockies, USA. Water, 2014 vol. 6, no. 4, pp. 745-777.

22. Benkhaya S., Mrabet S., El Harfi A. A review on classifications, recent synthesis and applications of textile dyes. Inorganic Chemistry Communications, 2020, vol. 115, no. 7, pp. 1-35

23. Gupta V.K. Application of low-cost adsorbents for dye removal a review. Journal of Environmental Management, 2009, vol. 90, no. 8, pp. 2313-2342.

24. Englande Jr A.J., Krenkel P., Shamas J. Wastewater treatment \& water reclamation. In: Reference Module in Earth Systems and Environmental Sciences, Amsterdam, Elsevier, 2015. 32 p.

25. Collivignarelli M.C., Abbà A., Carnevale Miino M., Damiani S Treatments for color removal from wastewater: state of the art. Journal of Environmental Management, 2019, vol. 236, pp. 727-745.

26. Drioli E., Giorno L. Membrane operations: innovative separations and transformations. Weinheim, Germany, Wiley-VCH Verlag $\mathrm{GmbH} \& \mathrm{Co} . \mathrm{KGaA}, 2009.578 \mathrm{p}$

27. Dawood S., Sen T. Review on dye removal from its aqueous solution into alternative cost effective and non-conventional adsorbents. Journal of Chemical and Process Engineering, 2014, vol. 1, no. 104, pp. 1-11.

28. Idan I.J., Abdullah L.C., Choong T.S., Jamil S.N.A.B.M. Equilibrium, kinetics and thermodynamic adsorption studies of acid dyes on adsorbent developed from kenaf core fiber. Adsorption Science \& Technology, 2017, vol. 36, no. 1-2, pp. 694-712.

29. Jiang L., Yu H.-T., Pei L., Hou X. The Effect of temperatures on the synergistic effect between a magnetic field and functionalized graphene oxide-carbon nanotube composite for $\mathrm{Pb}^{2+}$ and phenol adsorption. Journal of Nanomaterials, 2018, vol. 2018, pp. 1-13.
30. Wong S., Ngadi N., Inuwa I.M., Hassan O. Recent advances in applications of activated carbon from biowaste for wastewater treatment: a short review. Journal of Cleaner Production, 2018, vol. 175 , pp. 361-375.

31. Obotey Ezugbe E., Rathilal S. Membrane technologies in wastewater treatment: a review. Membranes, 2020, vol. 10, no. 5, pp. 1-28.

32. Dos Santos A.B. Reductive decolourisation of dyes by thermophilic anaerobic granular sludge. PhD-Thesis. Wageningen, The Netherlands, 2005. $176 \mathrm{p}$

33. Warade A.R., Gaikwad R.W., Sapkal R.S., Sapkal V.S. Study of removal techniques for dyes by adsorption: a review. International Journal of Advance Research and Innovative Ideas in Education, 2016, vol. 2, pp. 3851-3869.

34. Ji L., Zhang Y., Liu E., Zhang Y., Xiao C. Separation behavior of NF membrane for dye/salt mixtures. Desalination and Water Treatment, 2013, vol. 51, no. (19-21), pp. 3721-3727.

35. Volmajer J., Marechal A., Vajnhandl S., Jeric T., Simon E. Water in the textile industry. Treatise on Water Science, 2011, vol. 4, pp. 685-706.

36. Cervantes F.J. Environmental technologies to treat nitrogen pollution. London, IWA publ., 2009. $420 \mathrm{p}$

37. Anjaneyulu Y., Sreedhara Chary N., Samuel Suman Raj D. Decolourization of industrial effluents - available methods and emerging technologies - a review. Reviews in Environmental Science and Bio/Technology, 2005, vol. 4, no. 4, pp. 245-273.

38. Atul K., Pratibha C., Poonam V. A comparative study on the treatment methods of textile dye effluents. Journal of Chemical and Pharmaceutical Research, 2012, vol. 4, no. 1, pp. 763-771.

39. International Atomic Energy Agency. Application of ion exchange processes for treatment of radioactive waste and management of spent ion exchangers. Vienna, International Atomic Energy Agency, 2002. $115 \mathrm{p}$.

40. Slokar Y.M., Le Marechal A.M. Methods of decoloration of textile wastewaters. Dyes and pigments, 1998, vol. 37, no. 4, pp. 335-356.

41. Nidheesh P.V., Zhou M., Oturan M.A. An overview on the removal of synthetic dyes from water by electrochemical advanced oxidation processes. Chemosphere, 2018, vol. 197, pp. 210-227.

42. Hashemian S., Tabatabaee M., Gafari M. Fenton oxidation of methyl violet in aqueous solution. Journal of Chemistry, 2013, vol. 2013, pp. 1-6.

43. Raghavacharya C. Colour removal from industrial effluents: a comparative review of available technologies. Chemical engineering world, 1997, vol. 32, no. 7, pp. 53-54.

44. Rosario L.C., Abel G.E., Marta I.L. Photodegradation of an azo dye of the textile industry. Chemosphere, 2002, vol. 48, pp. 393-399.

45. Rekhate C.V., Srivastava J.K. Recent advances in ozone-based advanced oxidation processes for treatment of wastewater - a review. Chemical Engineering Journal Advances, 2020, vol. 3, pp. 1-84.

46. Gähr F., Hermanutz F., Oppermann W. Ozonation an important technique to comply with new German law for textile wastewater treatment. Water Science and Technology, 1994, vol. 30, no. 3, pp. $255-263$.

47. Samer M. Biological and chemical wastewater treatment processes. Wastewater Treatment Engineering, 2015, vol. 150, 212 p.

48. Zheng C., Zhao L., Zhou X., Fu Z., Li A. Treatment technologies for organic wastewater. Water Treatment, 2013, vol. 11, pp. 250-286.

49. Kumbasar E.A., Korlu A. Textile wastewater treatment. Croatia, InTechOpen, 2016. $124 \mathrm{p}$.

50. Murty S.D., Patel S.D., Soni R., Bhatt N. Isolation and identification of bacterial culture for azo dye degrading capability. International Journal of Research in Chemistry and Environment (IJRCE), 2012, vol. 2, no. 4, pp. 69-79.

51. Jamee R., Siddique R. Biodegradation of synthetic dyes of textile effluent by microorganisms: an environmentally and economically sustainable approach. European journal of microbiology \& immunology, 2019, vol. 9, no. 4, pp. 114-118.

52. Horitsu H., Takada M., Idaka E., Tomoyeda M., Ogawa T. Degradation of p-aminoazobenzene by Bacillus subtilis. European journal of applied microbiology and biotechnology, 1977, vol. 4, no. 3, pp. 217-224.

53. Idaka E., Ogawa T., Horitsu H., Tomoyeda M. Degradation of azo compounds by Aeromonas hydrophila var. 24B. Journal of the Society of Dyers and Colourists, 1978, vol. 94, no. 3, pp. 91-94.

54. Anjaneyulu Y., Chary N.S., Raj D.S.S. Decolourization of industrial effluents - available methods and emerging technologies - a 
review. Reviews in Environmental Science and Bio/Technology, 2005 , vol. 4, no. 4, pp. 245-273.

55. Choudhury A., Lansing S. Methane and hydrogen sulfide production from Co-digestion of gummy waste with a food waste, grease waste, and dairy manure mixture. Energies, 2019, vol. 12, no. 23, pp. 1-12.

56. Van der Zee F.P., Lettinga G., Field J.A. Azo dye decolourisation by anaerobic granular sludge. Chemosphere, 2001, vol. 44, no. 5 , pp. $1169-1176$.

57. Van der Zee F.P., Bouwman R.H.M., Strik D.P.B.T.B., Lettinga G., Field J.A. Application of redox mediators to accelerate the transformation of reactive azo dyes in anaerobic bioreactors. Biotechnology and Bioengineering, 2001, vol. 75, no. 6, pp. 691-701.

58. Carliell C.M., Barclay S.J., Shaw C., Wheatley A.D., Buckley C.A The effect of salts used in textile dyeing on microbial decolourisation of a reactive azo dye. Environmental Technology, 1998, vol. 19, no. 11, pp. 1133-1137.

59. Gnanapragasam G., Senthilkumar M., Arutchelvan V., Sivarajan P. Nagarajan S. Recycle in upflow anaerobic sludge blanket reactor on treatment of real textile dye effluent. World journal of microbiology and biotechnology, 2010, vol. 26, no. 6, pp. 1093-1098.

60. Yagub M.T., Sen T.K., Afroze S., Ang H.M. Dye and its removal from aqueous solution by adsorption: a review. Advances in $\mathrm{Col}$ loid and Interface Science, 2014, vol. 209, pp. 172-184.

61. Capar G., Yetis U., Yilmaz L. Membrane based strategies for the pre-treatment of acid dye bath wastewaters. Journal of Hazardous Materials, 2006, vol. 135, no. (1-3), pp. 423-430.

62. Hassan M.M., Carr C.M. A critical review on recent advancements of the removal of reactive dyes from dyehouse effluent by ionexchange adsorbents. Chemosphere, 2018, vol. 209, pp. 201-219.
63. Xu X.-R., Li H.-B., Wang W.-H., Gu J.-D. Degradation of dyes in aqueous solutions by the Fenton process. Chemosphere, 2004, vol. 57 , no. 7, pp. 595-600.

64. Sundrarajan M., Vishnu G., Joseph K. Ozonation of light-shaded exhausted reactive dye bath for reuse. Dyes and Pigments, 2007, vol. 75 , no. 2, pp. 273-278.

65. Popli S., Patel U.D. Destruction of azo dyes by anaerobic-aerobic sequential biological treatment: a review. International Journal of Environmental Science and Technology, 2014, vol. 12, no. 1, pp. 405-420.

66. Dos Santos A.B., Cervantes F.J., Van Lier J.B. Review paper on current technologies for decolourisation of textile wastewaters: perspectives for anaerobic biotechnology. Bioresource technology, 2007, vol. 98, no. 12, pp. 2369-2385.

67. Sala M., Gutiérrez-Bouzán M.C. Electrochemical techniques in textile processes and wastewater treatment. International Journal of Photoenergy, 2012, vol. 2012, pp. 1-12.

68. Lee J.-W., Choi S.-P., Thiruvenkatachari R., Shim W.-G., Moon H. Evaluation of the performance of adsorption and coagulation processes for the maximum removal of reactive dyes. Dyes and Pigments, 2006, vol. 69, no. 3, pp. 196-203.

69. Arslan S., Eyvaz M., Gürbulak E., Yüksel E. A review of state-ofthe-art technologies in dye-containing wastewater treatment - the textile industry case. Textile wastewater treatment, $2016.124 \mathrm{p}$.

70. Cervantes F.J., Pavlostathis S.G., Van Haandel A. Advanced biological treatment processes for industrial wastewaters. London, IWA publ., 2006. $360 \mathrm{p}$.

Поступила 26.04.2021 2.

\section{Информация об авторах}

Джубари Мохаммед Кадер, ассистент-лектор, кафедра топливно-энергетических технологий, Северный технический университет.

Алексеева Н.В., доцент кафедры технологических процессов, аппаратов и техносферной безопасности, Тамбовский государственный технический университет.

Базияни Гашин Ибрахим, магистрант, кафедра химии, Тамбовский государственный университет им. Г.Р. Державина.

Taxa Виляль Caаd, инженер-технолог, Завод по очистке воды Кармат Али, Басра ойл компани. 
UDC 66.067

\section{METHODS FOR REMOVING PIGMENTS FROM WASTE WATER}

Mohammed Q. Gubari ${ }^{1}$, mohammedqader1983@gmail.com

Nadezda V. Alekseeva ${ }^{2}$, alexejewa.nadja@gmail.com

Gasheen I. Baziyani³, gasheenbazeany@gmail.com

Bilal S. Taha 4 , bilalsaad_@@yahoo.com

1 Northern Technical University, 1530, Al-Sayada street, Mosul, 36001, Iraq.

2 Tambov State Technical University, 106, Sovetskaya street, Tambov, 392000, Russia.

3 Tambov State University named after G.R. Derzhavin, 33, Internatsionalnaya street, Tambov, 392000, Russia.

${ }^{4}$ Qarmat Ali Water Treatment Plant, Basra Oil Company, 5 20, Bab Al Zubair street, Basra, 61001, Iraq.

Relevance. Dyes and pigments are natural and xenobiotic compounds that are widely used in various fields of human activity due to their ability to impart color to objects. During the implementation of production with the use of pigments, wash water containing pigment is formed, which is most often waste water. As a result, the enterprise loses some of its valuable pigments and dyes, and the environment is exposed to technogenic impact. Various colorants in water have an adverse effect on the environment. Therefore, purification of waste water from pigments is an urgent problem.

Aim: finding the most efficient and cost-effective technological process for wastewater treatment from pigments and dyes.

Methods: collection, generalization and comprehensive analysis of data on methods of wastewater treatment from dyes and pigments.

Results. The paper considers the existing technologies of treatment of wastewater containing pigments and dyes and introduces the examples of Russian and foreign experience. It is shown that it is impossible to create a unified treatment technology of wastewater containing pigments and dyes, since the choice of a specific treatment is influenced by the characteristics of wastewater due to the production technology and the type of pigments and dyes. Nevertheless, it is possible to systematize the existing technologies for a more convenient and quick selection of the required technological process. The authors have described the mechanical, mass transfer, chemical and biological purification processes and analyzed both individual processes and a combination of several ones. The use of several processes in one technological stage of wastewater separation is the most efficient and cost-effective solution.

\section{Key words:}

Textile wastewater, dyes, physical treatment, biodegradation, adsorption, membrane treatment.

\section{Information about the authors}

Mohammed Q. Gubari, assistant lecturer, Northern Technical University.

Nadezda V. Alekseeva, associate professor, Tambov State Technical University.

Gasheen I. Baziyani, master student, Tambov State University named after G.R. Derzhavin.

Bilal S. Taha, process engineer, Qarmat Ali Water Treatment Plant, Basra Oil Company. 